\title{
Departmental leadership for learning in vocational and professional education
}

\author{
Annemarieke Hoekstra ${ }^{1 *}$ (D) and Paul Newton ${ }^{2}$
}

\author{
*Correspondence: \\ annemarh@nait.ca \\ ${ }^{1}$ Learning and Teaching \\ Commons, Northern Alberta \\ Institute Technology, 11762 \\ 106 Street NW, Edmonton, AB \\ T5G 2R1, Canada \\ Full list of author information \\ is available at the end of the \\ article
}

\begin{abstract}
Background: To maintain relevance, institutes for vocational and professional education (VPE) need to be responsive to changes in society and industry. This requires leaders and educators in VPE to keep developing themselves and their practices. In institutes for VPE many decisions regarding program curriculum and teaching practices are made at the department level. Yet, the preparation of department chairs in postsecondary contexts rarely focuses on improving teaching and learning. A substantive knowledge base regarding leadership of teaching and learning in VPE is lacking. A model of leadership for learning in VPE is proposed as comprising three elements: (1) developing a shared vision and goals; (2) promoting instructor learning; and (3) leading the educational program. The study explores ways in which seven chairs and associate chairs from western Canadian VPE institutes conceive of and enact leadership for learning in their departments. The paper thus aims to contribute to the building of a knowledge base on leadership for learning in VPE.
\end{abstract}

Methods: A multiple case study approach was used to explore chairs' conceptualization and enactment of their leadership for learning. Data collected included interviews with five chairs and two associate chairs from five departments across three institutes for VPE in western Canada. Observational data from department meetings and interviews with instructors were used to provide contextual information and corroborate our findings. In cross-case analysis, chairs' and associate chairs' conceptualizations and strategies were themed and categorized according to the three elements of leadership for learning as identified in the literature.

Results: Findings show great variability amongst study participants in beliefs regarding the importance of a shared vision and goals, and only one chair had taken steps towards developing a shared vision. All participants expressed that they value quality teaching and learning and have taken promising steps to promote instructor learning, yet in different ways. Leading the educational program was considered a common and expected part of the role of department chair. Participants' beliefs regarding the enactment of leadership for learning varied greatly and seemed idiosyncratic.

Conclusions: The proposed model of leadership for learning seems to hold promise for conceptualizing leadership for learning in the context of VPE. However, further studies will need to elucidate how each element of leadership for learning might best be enacted to optimize student learning in VPE departments. Such studies will need to consider the organizational and cultural context of the VPE department. Institutes for VPE may invest in leadership development programmes that allow chairs to develop 
leadership for learning practices. Institutes might also focus on enacting leadership for learning at the faculty and institute level.

Keywords: Vocational education and training, Professional education, Leadership for learning, Instructor learning, Professional development, Instructional leadership, Educational leadership

\section{Background}

Ongoing changes in society and industry require teachers and schools to be responsive and thus continuously (re)develop themselves and their practices (Darling-Hammond 2006; Nicholls 2001). Responsiveness to ongoing change is particularly relevant for vocational and professional education (VPE) (cf. Darwin 2007; Sirk et al. 2016). In this paper VPE refers to education that prepares students to become qualified for a particular profession, regardless of educational level (e.g. tradesperson, health care technologist, or human resource manager) (Anderson 2008). Typically, the purpose of VPE is understood as both improving the social and economic well-being of individuals as well as serving society by ensuring an educated workforce (Adams and Gamage 2008). To keep fulfilling this dual purpose, leaders and educators in VPE need to keep developing themselves and their practices to meet the needs of their learners and society (Sirk et al. 2016). The present paper focuses on the leadership of department chairs in this process.

Research in elementary and secondary education has shown that leadership may positively impact teaching and learning (Robinson et al. 2008; Hallinger 2011). Some studies suggest that this might also be the case in post-secondary education (Ramsden et al. 2007). The present paper uses the term 'leadership for learning' to refer to those approaches that "leaders employ to achieve important school outcomes, with a particular focus on student learning" (Hallinger 2011, p. 126). Note that this term includes elements of leadership of teaching and curriculum, as both support student learning. While quality teaching is considered an important prerequisite for student learning (Prosser 2013; Scheerens and Bosker, 1997), leadership contributes to this by inspiring and enabling the conditions that allow for optimal student learning (Hallinger 2011). Yet, the leadership preparation of department chairs in post-secondary contexts rarely focuses on improving teaching and learning and is "widely limited to legal matters, organizational procedures and doing the budget" (Knight and Trowler 2000, p. 81). Not only is there a lack of preparation for department chairs as educational leaders, there also seems to be little substantive knowledge base regarding leadership for learning in VPE (Burke 2014). In fact, much of the literature on leadership in post-secondary contexts draws heavily on business literature, which focuses on overall roles and responsibilities and rarely gives serious consideration to issues of teaching and learning (Basham and Campbell 2010; Crossman and Cameron 2014; Smith 2002). In the context of VPE specifically, Adams and Gamage (2008) identified the need for leaders to focus on the educational dimension of their work and suggested that the shift to managerial responsibilities is having an effect on leaders' abilities to ensure quality educational programming. A recent review of research into leadership in vocational education in Australia, the UK, and the USA highlights important issues that leaders in vocational education face (Crossman and Cameron 2014). Yet, the review does not mention studies that focus on how leadership affects teaching and learning. 
One important way in which educational leaders may impact quality teaching is by fostering teacher professional learning (cf. Hoekstra and Crocker 2015a, b; Robinson et al. 2008; Hallinger 2011). Studies into workplace learning suggest that leadership practices by direct supervisors may make a difference in fostering employee learning (Ellström and Ellström 2014). In institutes for VPE in Europe, teachers' perception of leadership practices have indeed been related to teachers' engagement in professional development in VPE (Oude Groote Beverborg et al. 2015b; Runhaar et al. 2010). While instructors' perception of leadership matters, these studies do not provide insights into how and why such leadership practices are enacted in their departments. Moreover, much research on leadership for teaching and learning has been quantitative and has been conducted in the context of K-12 education (cf. Geijsel et al. 2009; Leithwood and Jantzi 2006; Robinson et al. 2008). The present study therefore includes a qualitative exploration of leadership for learning, describing the ways seven department chairs ${ }^{1}$ and associate chairs in VPE conceptualize and enact their role as leaders of teaching and learning within the context of their department. This description illustrates the complex dynamics of teaching and leading in VPE departments, elucidating aspects of leadership that require further research, and generating suggestions for support for leadership development of chairs.

This paper begins with a description of VPE in western Canada and continues with an overview of leadership elements that in the literature have been identified as supportive of teaching and learning. This is followed by a description of the methods and findings of our interview study. The paper ends with implications for research and practice.

\section{Vocational and professional education in Canada}

Vocational and professional education (VPE) encompasses both trades education (e.g. carpenter, electrician, pipefitter) as well as degree studies that prepare for a specific job, such as nursing or social work (Anderson 2008). As such, VPE includes but is not limited to what in Europe is commonly referred to as vocational education and training (VET) and technical and vocational education and training (TVET) (Tripney and Hombrados 2013).

In western Canada, VPE is offered at non-research intensive post-secondary institutes, including polytechnics, community colleges, and teaching universities. As a comparison to a number of other countries readers of ERVET may be familiar with, VPE is offered at vocational schools and universities for applied sciences including:

- technical and further education institutes in Australia (Adams and Gamage 2008)

- further education institutes (Drodge 2002) and statutory universities (Smith 2002) in Great Britain

- community colleges in the USA (Crossman and Cameron 2014)

- middelbaar beroepsonderwijs (MBO) and hoger beroepsonderwijs (HBO) institutes in the Netherlands

- Berufsschulen and Fachhochschulen in German speaking countries

${ }^{1}$ In various VPE contexts, department chairs may also be referred to as department chairs, department heads, or head teachers. Although there may be subtle differences in role, in this paper, we consider these terms as interchangeable. 
VPE institutes need to be responsive to changes in society and industry. In western Canada these changes include increasingly diverse student populations and frequently changing industry standards (Darwin 2007; Harris et al. 2001). Economic changes such as dropping oil prices require economic diversification and new programs for students, such as programs in renewable energy technologies. There are also changes in educational approaches such as a move to more authentic forms of student assessment (cf. Stiehl and Lewchuk 2008). For departments in VPE, these changes mean that both instruction and curriculum need to support students in mastering tasks compatible with current industry practices. This currency is achieved in two important ways. First, those who teach in western Canadian VPE programs-that is, instructors-are themselves professionals in the programs they teach; carpentry is taught by carpenters, social work by social workers and so on. Second, curriculum is developed through active involvement from industry and professional associations. In fact, many VPE programs are accredited by national or provincial professional associations, while the curriculum for the trades is created by the provincial government in close collaboration with trades organizations. Figure 1 shows the various stakeholders connected with a department. Stakeholder influence and authority over the content and delivery of educational programs differ across departments.

Additionally, Fig. 1 shows how each department is embedded in its organizational context as part of a faculty as well as part of an institute for VPE. Faculties and institutes also have educational quality assurance processes to which departments are required to adhere. While department chairs are expected to lead teaching and learning within this multifaceted environment, the leadership preparation programs in VPE typically include generic leadership skills and do not focus on issues of leadership for learning. The present study focuses on the ways seven department chairs and associate chairs in VPE conceptualize and enact their role as leaders of teaching and learning within this complex departmental context. The next section describes on elements of leadership that, in the literature, have been associated with teaching and learning.

\section{Leadership for learning}

Forty years of research into leadership for learning in K-12 settings (primary and secondary education), have resulted in a sound knowledge base in this field of study (Hallinger 2011), yielding evidence that principal practices impact student outcomes indirectly. Some evidence suggests that university department heads may similarly impact teaching and learning in post-secondary education. Martin and colleagues (2003) found a relationship between how university department heads and subject coordinators themselves conceptualize and report to enact their role as leader of teaching, and how their followers perceived that leadership. Ramsden and colleagues (2007) subsequently established that university teachers' experiences of academic leadership (leadership of teaching) relates to their approach to teaching. These findings indicate that, similar to K-12 school principals, department heads may indirectly impact teaching and learning in post-secondary education.

Since a knowledge base of leadership for learning in the context of VPE is largely lacking (Burke 2014), we turn to insights derived from studies in K-12 and the general post-secondary education literature to frame our study. Where available we also 


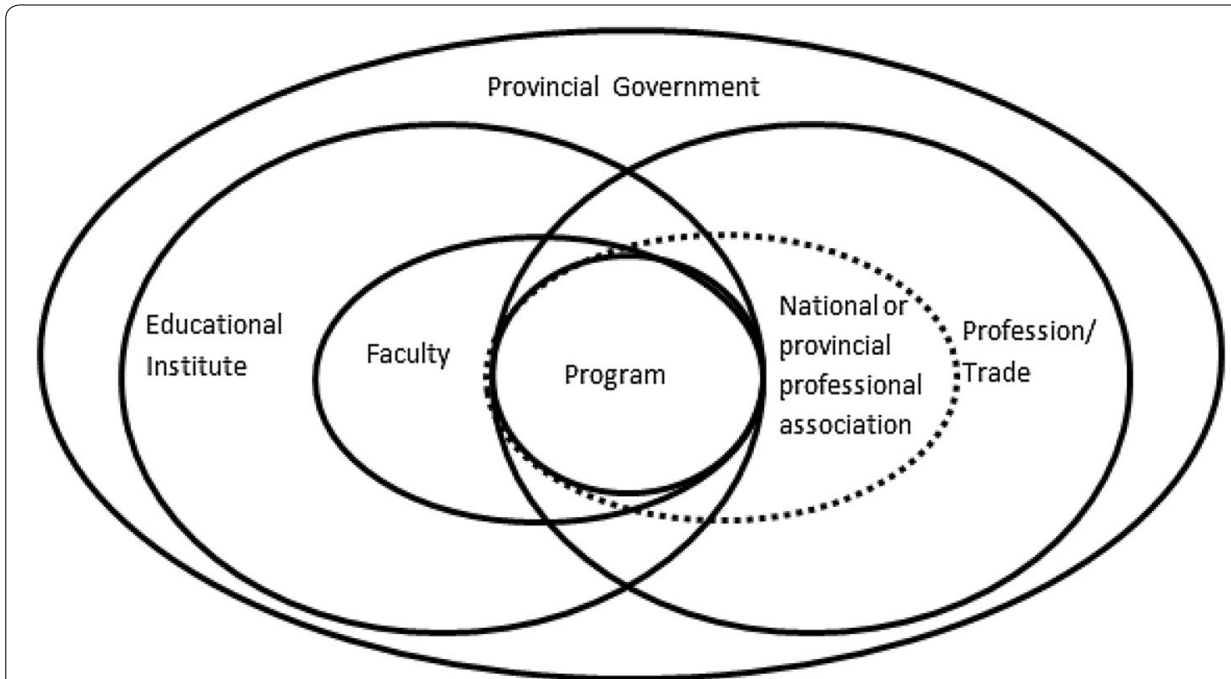

Fig. 1 Depiction of how VPE departments are situated within their context

describe studies conducted in the VPE context. As discussed in the introduction, we use the term "leadership for learning" to refer to those approaches that "leaders employ to achieve important school outcomes, with a particular focus on student learning" (Hallinger 2011, p. 126). In his synthesis of 40 years of research on leadership for learning in K-12 settings, Hallinger (2011, p 126) describes that leadership for learning "has come to subsume features of instructional leadership, transformational leadership, and shared leadership". Hallinger (2011) highlights three main paths through which leadership is linked to student learning: (1) vision and goals; (2) people capacity; and (3) academic structures and processes. These three elements correspond with the three main venues of transformational leadership identified by Leithwood and Jantzi (2006): (1) setting direction; (2) redesigning the organization; and (3) developing people. In Robinson and colleagues' (2008) meta-analysis of leadership studies in the K-12 context, it was concluded that three dimensions of leadership might hold promise for leadership for educational improvement. They are (with their average effect size): (1) establishing goals and expectations ( $E S=0.42)$; (2) planning, coordinating, and evaluating teaching and the curriculum $(E S=0.42)$; and (3) promoting and participating in teacher learning and development $(E S=0.84)$. Tasks associated with organizing the school environment, that is-strategic resourcing $(E S=0.31)$ and ensuring an orderly and supportive environment $(E S=0.27)$ - have a smaller effect on student outcomes. Because departmental leaders in VPE likely have less influence over the organization of the VPE institute than principals in K-12, and because these organizational elements have a smaller effect on student outcomes, the present paper focuses on three elements of leadership for learning with the bigger effect sizes: vision and goals, promoting instructor learning, and leading curriculum and instruction. In the following sections we will further elaborate on each of these three elements. A fourth section positions the department chair in the context of VPE organizations. 


\section{Vision and goals}

Theories on transformational leadership highlight the motivational power of a shared vision. Such a vision "inspires people to contribute, even sacrifice, their effort towards the achievement of a collective goal" (Hallinger 2011, p. 129). Communicating a strong vision and clear goals is theorized to stimulate motivational processes, both by inspiring a desire in teachers to move towards a common goal (i.e. goal-orientation) and by instilling a belief that they are, in fact, capable of accomplishing these goals (i.e. self-efficacy) (Leithwood and Jantzi 2006, p. 206; see also Oude Groote Beverborg et al. 2015a, b, c; Runhaar et al. 2010). Both goal-orientation and self-efficacy are important conditions for teacher learning (Oude Groote Beverborg et al. 2015c). In their study of technical vocational education and training (TVET) teachers in the Netherlands, Oude Groote Beverborg et al. (2015c) found little support for the notion that transformational leadership is directly connected to teacher self-efficacy. In another study Oude Groote Beverborg and colleagues (2015b, p. 12) found that "leadership practices, perceived goal and task interdependence and self-efficacy...jointly explain a significant amount of the variation of TVET teachers in professional learning activities." Our study explores whether department chairs consider vision building and goal setting as part of their role, and if so, how they enact this role.

\section{Promoting instructor learning}

Leadership for learning has the greatest effect on student outcomes through the support of teacher learning and professional development (PD) (Robinson et al. 2008). This leadership role encompasses far more than merely enrolling teachers in PD sessions. A recent study by Hoekstra et al. (2017) points out that a large part of instructor learning in VPE is focused on developing pedagogical content knowledge (PCK). PCK refers to the knowledge teachers require to adequately teach certain content. For instance PCK might include knowledge of the issues students face when they put a circuit box together, analyse a blood slide safely, efficiently, and accurately, or when they design a front yard in a cold climate. Because the content generally taught in VPE is relatively specialized, there are no formal PD opportunities for instructors to learn. Developing PCK, therefore, necessarily happens on-the-job. Empirical studies into teachers' continuous PD have increasingly identified teachers' workplaces as important sites for learning (cf. Bound 2011; Kwakman 2003; Kyndt et al. 2016; Sleegers et al. 2005). Workplace learning activities that have been related to teachers' PD and school improvement include: keeping up to date, experimentation with teaching strategies, self-reflection, asking for feedback, and information sharing (Hoekstra et al. 2009, 2017; Geijsel et al. 2009; Oude Groote Beverborg et al. 2015b; Runhaar et al. 2010). Leadership for learning would therefore include efforts to promote instructor workplace learning activities.

Leaders may promote instructor learning through transformational leadership practices. Oude Groote Beverborg et al. (2015c, p. 25) described transformational leadership as:

(1) identifying and articulating a vision which refers to the development of goals and priorities; (2) individual consideration, which includes attending to the feelings and needs of individual teachers; and (3) intellectual stimulation, which entails sufficient support of teacher professional development and the challenging of teachers to readdress their knowledge and daily practice. 
Oude Groote Beverborg et al. (2015a, p. 187) found that "transformational leadership practices play a significant role in facilitating teamwork, and sustaining teachers' levels of learning in schools." Runhaar and colleagues (2010) found that transformational leadership was positively related to teachers' reflection and feedback asking activities. Additionally, studies into leadership for learning in higher education have suggested that university teaching can be improved by encouraging collaboration and collegiality (e.g. Zakrajsek 2014), influencing the discourses of collegial networks (Roxa et al. 2011), and the provision of an "enabling environment" and "supportive workgroup" (Van Schalkwyk et al. 2015, p. 8).

Few studies have looked into how VPE instructors develop teaching expertise and maintain currency in their work. For instance, Bound (2011) described how VPE instructors' professional learning is determined both by individual efforts and shaped by preexisting institutional practices and cultures. Hoekstra and Crocker (2015a, b) studied the professional learning practices of VPE instructors in western Canada in the context of a new performance management process. They concluded that, in order to develop and maintain teaching excellence, institutes need to augment courses and workshops for instructors with concrete, long-term support for on-the-job learning. The performance management process allowed chairs to individualize their support for instructor learning and assist instructors in planning their future professional learning activities. Runhaar and Sanders (2013) looked at the implementation of an integrated human resource management policy in Dutch institutes for VET. This policy was often implemented with the aim to promote professional development and excellence amongst employees. However, one of the factors considered to impede implementation of the policy was the fact that many teachers found the performance management review not useful to their practice. Our study explores whether department chairs consider the promotion of instructor learning part of their role, and if so, how they enact this role. The use of performance management conversations is considered part of this role.

\section{Leading the educational program}

A third element of leadership related to student outcomes is leading curriculum and instruction (Robinson et al. 2008). Robinson and colleagues (2008) identified four ways in which leaders exert influence over the quality and direction of further development of curriculum and instruction: (1) by active involvement in collegial discussion of instructional matters; (2) by coordinating the curriculum; (3) by evaluating teaching through classroom observation; and (4) by monitoring student progress and using test results for program improvement. Two of these strategies-involvement in discussion of instructional matters, and classroom observation-strongly overlap with leadership to promote instructor learning (see previous section) which is why we do not include them in our category of leading the educational program. The other two-coordinating the curriculum and monitoring student progress-will be discussed here.

Leading the curriculum in VPE might involve different tasks and practices than in K-12 education, because no provincial or state curriculum is available. In VPE many educational programs create their own curriculum, often in collaboration with industry (e.g. Stiehl and Lewchuk 2008). Brown et al. (2002) surveyed leaders in 2-year colleges in the United States about their perceptions of the most needed skills for community college 
leaders. Among the top ten ranked skills for leaders was curriculum development. There is little research available outlining the role department chairs play in leading the curriculum development and review process (Jennings-Sweeney 2012). Jennings-Sweeney (2012) interviewed 13 Community College department chairs in the USA and found that chairs of accredited programs have more clarity and guidelines regarding their leadership of curriculum review development, while chairs of disciplinary programs act more as managers of the curriculum. More recently, Albashiry et al. (2015a, b, c) studied leadership of curriculum development in TVET institutes in Yemen, where, similar to institutes in western Canada, curriculum is created and updated in close collaboration with industry. Albashiry and colleagues (2015c) refer to 'curriculum leadership' as a central activity of Heads of Departments (HoDs) in Community Colleges, portraying curriculum leadership as a collective activity led by HoDs. They further argue a need for "the consideration of the curriculum-development competency domain in the professional preparation and practice of college HoDs" (p. 411). Briggs and colleagues (2003) established four criteria for continuous academic planning in undergraduate education, which also stress the importance of collaboration: (1) continuous and frequent curricular planning processes; (2) awareness of and responsiveness to internal and external factors; (3) participation and teamwork; and (4) evaluation and assessment for program improvement.

This last criterion of continuous academic planning refers to leading the educational program by monitoring its effectiveness. Robinson and colleagues (2008) found that high-performing schools used students' test-results for the purpose of school improvement. Similarly, in VPE, department chairs may assure program quality by evaluating program success and implementing improvement where needed. Available data that could be used to monitor program success include: graduate satisfaction surveys, student graduation rates, student performance on provincial or national exams, student employment rates, and employer satisfaction with graduate performance. The use of program data and assessment to facilitate collaborative decision making and planning about the educational program is a core leadership practice in effective educational institutes (Newton et al. 2010). Our study explores whether department chairs consider leading the educational program part of their role, and if so, how they enact this role.

\section{Departmental leadership in context}

While 40 years of research have resulted in some fairly consistent findings on what constitutes leadership for learning, Hallinger (2011) warns against the idea that there is one magic set of practices that would guarantee school improvement. Referring to his own studies into leadership for learning, Hallinger writes: "that leadership can be an important catalyst and supporting factor for school improvement, but that the schoollevels conditions ... always exercises an even stronger influence on leadership" (2011, p. 133). Leaders thus have to work within their context. In their study on transformational leadership in TVET institutes, Oude Groote Beverborg and colleagues (2015b) hypothesize that, in contrast to studies conducted in K-12 contexts, the complexity of the organizational environment of the TVET institution might decrease the effect of transformational leadership due to multiple levels of organization, units, and subunits in post-secondary contexts. In this respect, department chairs might be functioning more 
as middle managers and intermediaries (cf. Briggs 2005). Additionally, much of instructor professional learning happens on-the-job, and such learning is embedded in existing workplace practices (Hoekstra and Crocker 2015a, b; Hoekstra et al. 2017). Hoekstra and Crocker $(2015 \mathrm{a}, \mathrm{b})$ therefore stressed the need for department chairs to remove barriers and create opportunities in the workplace to support instructor learning.

Van Schalkwyk et al. (2015) show how in universities the leadership of teaching is embedded in the wider university culture where efforts to improve teaching might not be valued, and reward systems might not be supportive of instructors' development as teaching professionals. For the present paper, this means that departmental leadership needs to be understood within the wider context of the educational institution, with its opportunities and barriers for instructor learning, as well as its culture for learning and student success.

\section{Research question}

The main research question is: Do department chairs in VPE consider vision building and goal setting, promoting instructor learning, and leading the educational program as part of their role, and if so, how do they enact this role in the context of VPE?

\section{Methods}

This study is an exploratory multiple case study (Yin 1993) of five chairs and two associate chairs in five departments of three institutes for VPE in western Canada. A case study approach was adopted as a means to explore how department chairs conceptualize and enact their role as leaders of learning. In cross-case analysis the case specific themes identified in the data were compared and contrasted (Miles and Huberman 1994).

\section{Recruitment}

A research ethics proposal was drafted and approved to ensure compliance with Canada's Tri-Council Policy Framework for Research Involving Human Subjects. To protect the identity of the research participants, institutes, chairs, and instructors have been given pseudonyms and the participants' departments are described in broad terms. Three institutes were approached for this study. Prairie College is a large institute for technical education, offering trades and diploma programs and a few bachelor degrees. Mountain College is a teaching university with diploma and bachelor degree programs. River College is a community college with employment and upgrading programs as well as certificate and 2-year diploma programs. Upon receiving further research ethics approval from the three institutes, department chairs and deans were contacted to invite their department for inclusion in the study. They were informed that criteria for inclusion in the study were: having at least 10 instructors, and the program's primary function is preparing students for a specific trade or profession. Liberal arts and general science departments were thus excluded, while departments such as welding and human resource management were eligible. Five departments-three from Prairie College and one each from Mountain College and River College-accepted the invitation and contacted the researchers to volunteer their department for further recruitment in the study. 


\section{Data collection}

The research team then invited instructors, chairs and associate chairs within each of these five departments to participate in the study and these participants were requested to fill out an informed consent form. For the purpose of the present paper, we interviewed all five department chairs and two associate chairs from a total of five departments regarding their understanding of their role as leaders for learning in their departments, and the strategies they use to enact this role. The semi-structured interview guide was inspired by the interview guide used by Van Schalkwyk et al. (2015), however we amended it to serve our purpose. Our interview guide included questions such as:

- What would you say are your primary responsibilities as (associate) chair of this program?

- Do you consider it your role to build a vision for teaching and learning amongst instructors in your department? If so, what are some things you've done in this regard?

- Do you consider it your role to support instructor learning in your department? If so, what are some things you've done in this regard?

- What data do you use to establish whether the department is successful?

- Whose responsibility is it to create the programming and curriculum in your program?

While the chair and associate chair interviews form the main data source, we used additional data collected for other parts of our study to further understand the context in which the chairs work, and to triangulate the interview data. These additional data include notes made during observation of a number of staff meetings in each of the five departments, and interviews with four to eight instructors in each department about their professional learning, and the factors that support or hinder their professional development.

\section{Data analysis}

Interviews with department chairs and associate chairs were audio-recorded and transcribed verbatim. To analyse department chairs' role conception, we identified statements prefaced with the following phrases: 'It is my responsibility ..., 'I have to ..., 'I see it as my job ..., 'I am required to...' We then themed these statements, where possible, using concepts from the literature as sensitizing concepts (Bowen 2006): vision and goals, promoting instructor learning, and leading the educational program. An additional theme regarding role-conception emerged inductively from the data: role conception regarding operational and management requirements. We similarly themed chairs' enactment of their role, using sensitizing concepts such as: promoting on-the-job instructor learning, and using performance assessment to promote instructor learning. Again, additional themes emerged from the data, including fostering instructors' connections with the field, and leveraging institutional support for instructor learning. Our final list of themes, ordered by element of leadership for learning is as follows. Emergent themes have been identified with (e): 
a. Vision and goals

1. Role-conception regarding vision and goals

b. Promoting instructor learning

2. Role conception and beliefs regarding quality teaching and instructor learning

3. Promote formal learning of instructors

4. Promote instructor connections with the field (e)

5. Promote on-the-job learning

6. Leverage institutional support for instructor learning (e)

7. Promote instructor learning through performance assessment cycle

c. Leading the educational program

8. Role conception regarding the curriculum

9. Leading (enacting) quality curriculum

10. Role conception regarding student learning (e)

11. Fostering quality learning for students (e)

Three other themes that were not related to the three themes of leadership for learning, but that provided useful background information include: (12) role conception and enactment of administrative tasks, (13) organizational barriers to instructor learning, as well as a theme regarding the (14) leadership preparation participants received. To further investigate these themes in the interviews, we created a summary matrix (Miles and Huberman 1994, p. 93-95) creating one column per participant, and one row for each theme. In each cell we then summarized the participants' beliefs or strategies, with reference to the original transcript excerpts. In the findings section we describe the results of this analysis.

\section{Description of sites and participants}

Table 1 provides an overview of the participants and some characteristics of the departments in which they work. All programs are post-secondary programs. Before entering the trades program, students must have completed a minimum of grade 10 (taken by 16 year olds), which means they have completed a minimum of 4 years of secondary education. Students entering the diploma programs are 17 or 18 years old and have completed high-school, which in western Canada is 6 years of secondary education. Please note that college and participant names are pseudonyms, and program names are not provided, to ensure the anonymity of the participants.

Each chair in this study had been associate chair before becoming chair. Corey had just become chair at the start of the study, but had been associate chair of the department for 2 years before becoming chair.

The curriculum in the trade program is regulated by the provincial government's ministry responsible for trades. Students are officially registered as apprentices with the provincial trades department, which also provides the full curriculum to institutes, including the learning modules for the trade. At the end of their training, apprentices complete the provincial trade exam to become certified by the provincial government. Apprentices attend trades education at Prairie College for a 2 or 3-month period per year, spending the rest of the year working as apprentices in the trade. The curriculum in the other four programs is the responsibility of the departments themselves. Each of the 
Table 1 Overview of Sites and participants

\begin{tabular}{|c|c|c|c|c|c|}
\hline College & Sector & Program & $\begin{array}{l}\text { Number } \\
\text { of instructors }\end{array}$ & $\begin{array}{l}\text { Leadership } \\
\text { team }\end{array}$ & $\begin{array}{l}\text { Participants' } \\
\text { pseudonyms, } \\
\text { role, and length } \\
\text { of time in role }\end{array}$ \\
\hline Prairie College & Trade & Apprenticeship & $>40$ & $\begin{array}{l}1 \text { chair } \\
4 \text { associate } \\
\text { chairs }\end{array}$ & $\begin{array}{l}\text { Blake (chair, } \\
6 \text { months) } \\
\text { Drew (associate } \\
\text { chair, } 2 \text { years) }\end{array}$ \\
\hline Prairie College & $\begin{array}{l}\text { Health technol- } \\
\text { ogy }\end{array}$ & 2 year diploma & $25-40$ & $\begin{array}{l}1 \text { chair } \\
3 \text { associate } \\
\text { chairs }\end{array}$ & $\begin{array}{l}\text { Parker (chair, } \\
3 \text { years) } \\
\text { Lane (associate } \\
\text { chair, } 2 \text { years) }\end{array}$ \\
\hline Prairie College & Business & $\begin{array}{l}2 \text { year diploma } \\
3 \text { and } 4 \text { year } \\
\text { degree }\end{array}$ & $25-40$ & $\begin{array}{l}1 \text { chair } \\
3 \text { associate } \\
\text { chairs }\end{array}$ & $\begin{array}{l}\text { Connor (chair, } \\
2 \text { years) }\end{array}$ \\
\hline River College & Health service & 2 year diploma & $>40$ & $\begin{array}{l}1 \text { chair } \\
4 \text { associate } \\
\text { chairs }\end{array}$ & $\begin{array}{l}\text { Corey (chair, } \\
3 \text { weeks) }\end{array}$ \\
\hline $\begin{array}{l}\text { Mountain } \\
\text { College }\end{array}$ & Human service & $\begin{array}{l}2 \text { year diploma } \\
4 \text { year degree }\end{array}$ & $<15$ & 1 chair & $\begin{array}{l}\text { Sam (chair, } \\
7 \text { years) }\end{array}$ \\
\hline
\end{tabular}

four departments work closely with the professional association their diploma/degree is affiliated with to ensure the curriculum adequately prepares students for the profession.

\section{Findings}

In this section we describe the outcomes of our interview analysis, organized by element of leadership for learning: (1) vision and goals; (2) promoting instructor learning; and (3) leading the educational program.

\section{Vision and goals}

Our first interview question focused on whether chairs and associate chairs consider it their role to build a vision for teaching and learning within their department.

We asked Blake: "Now that you're chair, do you consider it your role to build a vision for teaching and learning in your department?" S/he responded:

Yes. Absolutely. I think, and part of that vision is the vision of excellence, I guess and that, I think is really the real challenge. You know, you always have the percentage of instructors that are really excited about what they're doing, and really engaged, and then you have a group that, you know, they go in, they do their job, but that's it. And to engage them in-in being more proactive to engage the students and get the students involved, that's the challenge, I think.

When asked about their vision for teaching and learning, both Parker and Lane expressed that they do not see it as their responsibility to build such a vision, rather to have their department follow the vision of teaching excellence as set forth in the Faculty of Health Sciences and the institute. Parker, for instance, responded: "so Prairie College kind of says, 'here's what we think is ... good teaching and learning,' and then it's my job to help staff reach that goal." Lane explained that their Faculty of Health Sciences has their own official documentation of standards for teaching quality. After a long 
explanation, we asked: "It sounds like the faculty [of health] has a vision for what good teaching looks like, and that you're trying to get your instructors to become familiar with that, and to comply with it?" and Lane responded: “That's what I'm trying to do. Isn't that my job?"

When asked about his/her vision for good teaching, Connor described "engaged teaching" and "empowerment for students". S/he highlighted that good teaching should be focused on "moving students ahead" and "using [students'] time well." When asked: "Is it your role to communicate your vision to instructors and to staff?" Connor replied: "That's probably a little bit unclear." S/he expanded on this by saying: "I think one of the things that I need to do is to certainly help to ensure that they [the instructors] have some kind of a vision for what they want to do, or at least work with them on that."

We asked Sam whether s/he considers it the chair's role to build a vision amongst instructors for teaching and learning. Sam replied: "I do think it's my role to support the development of a vision or program learning outcomes and all of that, but I don't think it's my role any more than anybody else's to actually create them or make them." Sam then explained that, along with colleagues, they formulated a shared vision for the department a few years back.

In sum, when asked about working towards a vision of quality teaching and learning, most participants agreed that this was part of their role. However, only one chair enacted a practice that might be construed as a transformational leadership action related to goals and vision. All participants, however, agreed that promoting instructor learning was an important part of their role. As the following sections show, each chair and associate chair seemed to enact this role in different ways.

\section{Promoting instructor learning}

When asked about their primary responsibility, each of the chairs and associate chairs listed a great number of administrative tasks. This concurs with findings from a recent survey study amongst department chairs (Gmelch et al. 2016) and earlier studies such as Knight and Trowler (2000). Yet, each chair and associate chair we interviewed indicated that they value quality teaching and have taken steps towards encouraging instructor professional learning. The chairs expressed a variety of beliefs about instructor learning, including Blake: "It's a growth process ... you constantly have the opportunity to improve yourself". Connor, however, working in the business department described his/ her beliefs differently:

I don't know if it's that easy to try to make people who are, you know, trained in other disciplines, to make them instructors. ... I'm kind of a little more of the belief that teachers are born, not made. ... I think people that end up in that role here are a lot of people that actually are pretty good at teaching.

Chairs in the two health sciences departments indicated that instructors in their departments display a great willingness to learn. Parker: "The people I work with are really passionate about student learning and want to be the best they can be." Corey: "I just get this overall sense that people [at River College] are enthusiastic about all kinds of learning." 
As each of our participants found instructor learning important, each reportedly employed a wide variety of strategies to encourage and support instructor professional learning. In this way, the participants appear stronger in enhancing people capacity, than on building a shared vision (Hallinger 2011). The enactment of leadership is demonstrated through a variety of strategies employed. These strategies can be organized in four themes: (1) fostering participation in formal professional development opportunities; (2) fostering instructor connections with the field/clinic/industry; (3) fostering informal instructor learning; and (4) encouraging instructor self-directed learning and learning from feedback through performance review cycles.

\section{Fostering instructor participation in formal professional development opportunities}

Each of the three colleges in our study provides individual funding for instructors to attend conferences and courses. In addition, the three colleges each have a dedicated department offering courses and/or workshops on a variety of teaching topics. In the two health sciences departments and the business department, participating in a number of hours of formal PD is a requirement to stay registered as a professional in that field and employed in the department. Thus, chairs support instructors by approving time and funding for PD attendance. Sam, who chaired a department with a relatively small number of instructors, supported instructors' formal PD when they devised their workload plans at the beginning of the academic year. Sam supported them, for instance, by writing letters of support when instructors applied to attend conferences.

While enabling conference attendance is an administrative task chairs are required to perform, the chairs in our study enacted their leadership for learning by organizing customized sessions, inviting speakers to staff meetings and by organizing substitute teachers, and requesting instructors to share what they have learned. Specifically, three departments have worked together with their teaching department, or other training providers, to provide sessions customized to their department on issues such as lesson planning, the institutional learning management system, and difficult conversations with students. Corey, in River College, also regularly invited speakers to the monthly mandatory staff meetings to provide relevant information and training. Blake and Drew in the trades department reported that instructors do not have many opportunities to participate in PD because of the many hours they are required to teach. In their department there is only 1 week in the year when instructors are at work, but do not need to teach. In their case, facilitating instructor PD involved approving funds to attend PD and organizing substitute instructors for classes missed. The instructors in their department who attended external PD sessions were required to write a report and circulate it amongst their colleagues.

\section{Fostering instructor connections with the field}

In addition to fostering participation in formal PD, the chairs in our study also worked towards keeping instructors connected to their trade/profession. Lane and Parker, for instance, approved industry leaves that allowed instructors to take a leave of absence from their instructor role to go back to work in the field for a limited time. Other chairs allowed instructors to work in the profession on a part time or casual basis (Corey, health sciences; and Connor, business). Because of their heavy teaching load, Blake and 
Drew indicated that industry connections mostly happen through attending industry events, such as conferences, or in specific training sessions put on by manufacturers of new technologies that have become part of the curriculum. In the social services department, there is an expectation that instructors engage in service, both within the institute as well as in their profession. Sam explained that this means that instructors are expected to "be involved with the professional association, ... be on educational committees for people in the field ...' Since accommodating instructors' connections with the field is at the discretion of the chair, the chairs in our study enacted leadership of learning by valuing, encouraging, and accommodating instructor employment or service in the field.

\section{Fostering informal instructor learning}

Common in each department was the provision of a shared digital space, where instructors could upload their teaching materials for their colleagues to use and adapt. The large trades department seemed to have the most extensive culture of informal learning, where instructors welcomed each other into their classes, and new instructors were encouraged to observe other instructors' classes prior to teaching the same content on their own. Many instructors also worked together on developing an extensive online bank of student assignments. In addition, instructors in this trades department typically provided each other with teaching materials and walked each other through it. Instructors taught certain classes in pairs, contributing to mutual learning. In addition, Blake recently started requiring that new instructors be paired up with a mentor, and observe specified classes taught by their colleagues.

The business department, on the other hand, had a more individualized culture. Apart from the first year courses, instructors who taught the same course worked in small groups to align pacing of content, quizzes and exams. From the instructor interviews we learned that, at times, the course coordinator prescribed rather than collaborated, inhibiting others from bringing forward ideas and engaging in discussion. Upon request, Connor indicated that $\mathrm{s} / \mathrm{he}$ has made space in the schedule for instructors to observe colleagues who are already teaching the course they intend to teach in the future. At the start of his/her appointment as chair, Connor recognized that instructors in his/her department were not able to meet all together at any point in the work week, due to the fact that there were always some instructors scheduled to teach at any given time of the working day. S/he therefore worked with the Faculty of Business to create one hour in the teaching schedule per week where instructors are not teaching, so that there was time for instructors to attend a meeting or customized workshop.

Other chairs employed alternative strategies: Corey encouraged the creation of learning communities of instructors who are working on similar courses or similar delivery formats. Sam seems to have implemented the least innovations regarding fostering informal instructor learning, possibly because s/he did not see a clear need. The instructors in the small department that Sam chaired are accustomed to collaborating on a wide variety of department activities. At the end of each academic year, this group of instructors comes together for two full days of program planning in which they evaluate initiatives of the past year and devise a plan for changes to be made in the new academic year. 
Regarding fostering informal learning amongst instructors, our findings show that three chairs in our study enacted leadership for learning by expanding existing opportunities for instructors to learn from each other.

\section{Fostering instructor learning through the performance management cycle}

At the time of study, each of the three institutes had a process in place for instructors and their chair to meet to discuss goals for the year, and at the end of the year to assess their progress towards these goals. At Mountain College a peer evaluation process was part of the performance management cycle, whereas at Prairie College there was an effort to encourage instructors to collect feedback from multiple sources on multiple aspects of their job, including teaching, corporate citizenship, and curriculum development. As such, the performance management cycle was to be used by chairs to individualize their support for instructor professional learning. While the chairs we interviewed aimed to follow this process, two chairs took initiative to increase the learning potential of the performance management cycle by incorporating classroom observation into the process. Blake asked each associate chair to conduct classroom observations with all their newer instructors, and use a feedback template to fill in during the observation. Lane also started conducting supervisory classroom observations with the instructors reporting to him/her.

In sum, promoting instructor learning was generally accepted as part of the role of department chair. Chairs enacted this role in different ways and to different degrees. The chairs in our study went beyond their administrative duty to approve funding for PD, and enacted their leadership for learning by organizing substitute teachers, customized sessions, and guest speakers. They also valued, encouraged, and accommodated instructor employment or service in the field (trade/profession) and four of the five chairs expanded existing opportunities for instructors to learn from each other. Finally two chairs enacted leadership for learning by incorporating classroom observation into the performance management cycle.

Considering that the participating chairs had limited support in developing their leadership practice, these findings are promising as leadership practices by direct supervisors can make a difference in fostering employee learning (Ellström and Ellström 2014). Additionally, while VPE instructors' perceptions of leadership practices have been related to instructor engagement in ongoing PD (Oude Groote Beverborg et al. 2015b; Runhaar et al. 2010), our findings illustrate how, why, and under what circumstances department chairs enacted "promoting instructor learning" as an element of leadership for learning.

\section{Leading the educational program}

The departments varied in the extent to which they had control and autonomy over their curricula. Apart from Blake and Drew, whose curriculum was provided by the government, each of the chairs and associate chairs considered it an important part of their role to lead quality curriculum, but to different degrees and levels. Each department was also in close contact with one or more professional associations that provided regulations such as graduate competency overviews and accreditation requirements. In addition, each institute had curriculum development policies and other quality assurance 
requirements. Connor's department had gone through a process of program curriculum mapping as part of Prairie College's efforts to create more consistency and quality across its programming. The first day of the program mapping exercise involved a day with industry representatives, who provided input into the expectations they have for the knowledge and skills of program graduates. The result of the mapping process was a graduate profile, a list of program learning outcomes, as well as a collection of course descriptions, which included descriptions of course learning outcomes and assessments. These activities are aligned with the curriculum leadership tasks of 'promoting collaboration' with teachers and representatives from industry and 'establishing purpose' (Albashiry et al. 2015c). The health department at Prairie College had gone through a similar mapping process, but in addition, Lane and Parker had invested time to review course documents and materials in more detail. Lane stated:

I audit teachers' courses; I review [Learning Management System] sites using a checklist; I review curriculum to ensure that they meet the program outcomes, so, and then they have the appropriate course outcomes, and then their concepts, skills and issues match the course outcomes, followed by the learning objectives. ... I review formative and summative assessments to ensure that they're high level thinking, and that they're testing to what they say they're testing to.

Sam, on the other hand, indicated that he/she leads curriculum mostly through collaboration, leaving the responsibility over individual courses with the instructor. We asked Sam whose responsibility it is to create the curriculum in his/her program. Sam replied:

I'd say it's shared. [In a two day retreat after the spring semester] we all discuss what needs to change or what needs to stay the same or what we're lacking in. ... Now, the primary writing responsibility [of the master course syllabus] typically goes to the instructor that will teach the course.

Chairs also used student performance indicators as feedback on the quality of the program. Three departments in the study feed into professions that provide provincial or national exams. The professional associations share the exam results in such detail that departments can identify clusters of content that students either excel in or are weak in. The chairs confirmed that they feed this information back to instructors to further improve teaching and curriculum. Other sources of information that chairs provided to the instructors are student performance during practicums and clinical placements, and graduate employment rates. However, the chairs valued and used this information to differing degrees. For instance, in meetings of the health technology program, the health service program, and the human service program we observed instructors sharing information about student performance on professional association tests and in field placements and active discussion amongst instructors of what the data meant for teaching and curriculum in the program.

In sum, leading curriculum development and renewal was a common and expected part of the role of department chairs of programs who were responsible for their own curriculum. The findings of this study suggest that the criteria Briggs and colleagues (2003) developed for academic programming in undergraduate education (continuous curriculum development and renewal processes, awareness and responsiveness, 
participation and teamwork, evaluation for program and curriculum improvement) can also be applied to educational programs in VPE, yet might need adaptation to describe the way industry partners might be engaged in the program planning and renewal process.

\section{Discussion}

The methods used in this study have common limitations associated with qualitative studies, such as small sample size and the fact the study was conducted within one single geographic region. Yet, some important observations can be made that might inform future research and practice. To summarize, our findings showed that:

1. Most participants agreed that working towards a vision of quality teaching and learning was part of their role, yet only one department chair had collaboratively developed a vision statement with the instructors of his/her department.

2. All chairs promoted instructor learning, yet in different ways and to different degrees.

a. In addition to approving funding for PD, chairs in our study organized customized sessions, invited speakers, and arranged for substitute instructors so that main instructors can attend formal PD.

b. Chairs fostered connections with the profession/trade by encouraging and accommodating industry leaves and service to the profession.

c. In three departments, chairs expanded opportunities for instructors to collaborate and learn from each other either by creating space in the teaching schedule for meetings, by encouraging learning communities, or by promoting mentoring of new instructors.

d. Two chairs enhanced the existing performance management cycle by incorporating classroom observation into the process.

3. Leading the educational program is a common and expected part of the role of department chair. The chairs in this study demonstrated concrete leadership actions in the area of curriculum leadership and approached this work collaboratively with industry partners and instructors. Chairs gathered and used information from both internal and external sources to assess the quality of the educational program(s) offered by their department.

\section{Implications for theory and research}

Our findings illustrate that in addition to aspects of transformational leadership, research on leadership for learning in VPE would also need to: (1) focus on what it is that VPE programs aim to achieve; (2) incorporate leadership of the educational program; and (3) consider the organizational and trade/professional context of the educational program. Below we discuss each of these elements in more detail.

\section{Do not only focus on how to lead, but also on what to achieve}

Most striking in this study was the apparent lack of importance placed on developing a shared vision within the department. In the absence of a shared vision and goals, the 
chairs' leadership practices appear ad hoc. For instance, chairs who organized customized sessions for instructors did so in response to student and instructor concerns. Goals for student learning remained implicit. Hallinger (2011) points out that "Goals also impact performance by limiting staff attention to a more narrow range of desired ends and scope of activities... They help to clarify what we will do and what we will not do" (2011, p. 129-130). While the quantitative studies by Oude Groote Beverborg and colleagues (2015a, b, c), and Runhaar and colleagues (2010), both found a relation between perceptions of transformational leadership and teacher learning in VPE, neither study indicates whether this learning is, in fact, aimed at a common vision or goal, as the studies did not focus on the content of teacher learning. The transformational leadership model thus may be limited in its application to leadership for learning in VPE, as it does not guide leaders in focusing their vision and goals on student learning outcomes. Studies on leadership for learning in VPE should thus not only answer the question whether there is a shared vision and goals and whether this promotes instructor learning (cf. Oude Groote Beverborg et al. 2015a, b, c; Runhaar et al. 2010), but studies should also focus on what the vision and goals are, and whether the content of the professional learning outcomes of instructors are aligned with those goals. Hallinger's (2011) model of leadership for learning is a values-based leadership model. Hallinger explains that this includes both instrumental and terminal values. Instrumental values describe "How we do what we do" (2011, p. 128), such as integrity, support, and respect. Terminal values refer to "What we want from our schools and students" (2011, p. 128), such as, for instance, academic achievement and equity in learning. Incorporating values-based leadership into a model of leadership for learning in VPE seems better suited to the VPE context than transformational leadership alone.

\section{Incorporate a focus on leadership of the educational program}

Our findings illustrate how department chairs enact leadership for learning by leading curriculum development and program assessment activities. This important leadership role has received very little attention in the literature on leadership in VPE (Albashiry et al. 2015c; Jennings-Sweeney 2012). As curriculum development in K-12 education is not usually the responsibility of individual schools, curriculum development is also not often highlighted in models of leadership for learning in K-12 education. Researchers of VPE may instead turn to the higher education literature for conceptualizations of leadership of the educational program. For instance, the criteria for academic programming for undergraduate education developed by Briggs and colleagues (2003) could be used as a starting point to highlight the responsibilities involved in leading an educational program in VPE. Our findings suggest that to be applicable to VPE, these criteria should be adapted to incorporate the participation of industry partners in the development and review of the VPE program.

\section{Consider the context}

Bound (2011) argued that the study of teacher professional learning needs to be highly contextualized. Similarly, our study shows an influence of: (1) organizational values and beliefs; (2) organizational barriers; and (3) the wider cultural context of the VPE department on leadership for learning by department chairs. 
First, our study into departmental leadership in VPE revealed an influence of organizational values and beliefs regarding departmental leadership on the role conception of department chairs. For instance, our findings revealed ambiguity amongst department chairs regarding their own role as a leader of quality teaching. This ambiguity seems to stem from a tension between values of academic freedom and collegiality on the one hand and the desire for leadership of teaching on the other hand. This tension came forward specifically in the two departments offering degree programs. Chairs and instructors across departments do not seem to agree whether the chair should be considered as supervisor of teachers (as in the K-12 sector, characterized by formal supervisee observation and evaluation) or as first amongst equals (as in the university context, characterized by faculty autonomy and limited direct supervision by department chairs). The study of leadership for learning by department chairs thus needs to take into account the ways in which the chair position is organizationally and culturally situated.

Second, the context of leadership for learning is relevant, in that organizational barriers may impede department chairs' efforts to lead teaching and student learning. For instance, our study showed how in several cases, the lack of flexibility in instructor schedules did not allow for collaborative professional learning or programmed professional development. One chair was able to arrange, within the faculty, for all instructors in his/her department to have one common hour where none of the instructors were scheduled to teach. Evidently, such scheduling issues need addressing at the faculty or institutional level, and chairs can be important advocates. Another barrier to instructor learning evident in the research was high teaching load.

Third, the wider cultural context of the VPE department is relevant in considering departmental leadership for learning. Our findings showed that some chairs' and instructors' departments were more actively involved in helping create curriculum quality guidelines and/or accreditation requirements and were therefore able to influence their context. These leadership activities, or absence thereof, seem to be related to beliefs regarding the purpose of education provided in the program. Is the program: (1) preparing students for participation in industry; (2) partner to shaping industry practices; or (3) leader of industry best practices? These beliefs are in turn related to questions regarding the responsibility of VPE in society: either to reproduce existing practices or be a leader of innovative change, and environmental and social responsibility (Anderson 2008).

In sum, leadership for learning by department chairs in VPE needs to be considered within the structure and culture of the educational institute it is part of, as well as in the wider cultural and political positioning of VPE in industry and society.

\section{Implications for practice}

Implications for practice point to a need for leadership preparation programmes for department chairs, as well as an institutional approach to leadership for learning.

\section{Need for leadership development programmes}

Our findings illustrate a range of activities chairs undertake to enact leadership for learning. Yet, lack of time, role ambiguity, and limiting beliefs may hamper the potential positive influence of departmental leadership on instructor learning and teaching. 
To address these issues, institutes for VPE may invest in PD programmes for department chairs, highlighting and clarifying role expectations, while allowing for diversity of practices, as required by external program stakeholders.

These PD programmes would need to stress the importance of vision building, as well as support chairs in developing a vision of teaching and learning within their departments. Leadership development programmes might also be designed with leadership of apprenticeship experiences as part of the overall curriculum.

In addition to formal PD, chairs may also be supported in their development of leadership for learning, by allowing prospective chairs to observe and participate in the work of chairs. Similarly, it might be fruitful to encourage opportunities for chairs to share experiences and ideas about the way in which they have enacted leadership for learning in their intuitional and policy contexts. This would have the effect of providing chairs and prospective chairs with a larger repertoire of leadership for learning practices.

\section{Need for institutional leadership for learning}

The Carnegie Foundation for the Advancement of Teaching (2008) has recognized the need for an institutional approach to strengthening education in Community Colleges, and has highlighted the importance of leadership at the institute level for teacher professional learning. Three departments in our study are part of the same institute, yet the department chairs show great variability in role conception and leadership practices. Standards and goals for quality teaching and student learning are either not consistent or not made explicit. Thus, in addition to clarifying role expectations and providing PD programming for department chairs, institutes may also enact leadership for learning at the institutional level. For instance, institutes could develop a shared vision and goals for student learning at the institutional level, along with a set of terminal values for instructor and student learning that may guide vision building and goal setting for student learning in faculties and departments.

Additionally, leaders at the faculty and institutional level could further support chairs in identifying and removing organizational and cultural barriers to instructor learning, for instance by allowing room for meetings in instructors' teaching schedules and by promoting flexibility amongst instructors to facilitate substitute teaching. Processes to evaluate and reward the development of teaching practices by instructors might allow institutes to demonstrate the value of teaching and learning for the institute. Finally, an institutional approach to the sharing of leadership practices might prove successful in instilling high standards of leadership for learning across departments.

\section{Conclusions}

The participants in this study were clearly active in leading their academic units within complex institutional contexts. Most of our participants had considerable leadership responsibilities in the area of curriculum development and renewal in particular. Even though our participants have all thought carefully about their roles in teaching and learning, there appears to be an underdeveloped sense of what leadership of teaching and learning means in their institutes. As well, the systems and practices for supporting instructor professional learning (even within the same institutes) seem idiosyncratic. The work of these educational leaders is central to the quality of teaching and programming 
in VPE. A more systematic and considered approach to leadership for learning is needed to ensure high quality teaching and learning in VPE.

\section{Abbreviations}

PD: professional development; VPE: vocational and professional education.

\section{Authors' contributions}

Both authors contributed substantially to each stage of the research process. Both authors read and approved the final manuscript.

\section{Author details}

${ }^{1}$ Learning and Teaching Commons, Northern Alberta Institute Technology, 11762106 Street NW, Edmonton, AB T5G 2R1, Canada. ${ }^{2}$ Educational Administration, University of Saskatchewan, 28 Campus Drive, Saskatoon, SK S7N 0X1, Canada.

\section{Acknowledgements}

The authors would like to thank students of NAIT's Captioning and Court Reporting program as well as Holly Aamot for their assistance in transcribing the interviews. Many thanks to Ewa Wasniewski for her assistance with portions of the analysis, as well as thanks to Pamela Timanson, Jodi Lommer, Erin Magee, and Kristine Pederson for their help with editing various versions of the manuscript. Finally, our thanks go to Kelly Ward and the two blind reviewers for their insightful and constrictive feedback.

\section{Competing interests}

The authors declare that they have no competing interests.

\section{Ethics approval and consent to participate}

This study was conducted in compliance with Canada's Tri-Council Policy Framework for Research Involving Human Subjects. Research ethics approval was received from the Research Ethics Board of the Northern Alberta Institute of Technology, as this is the home institute of the first author. Subsequently, research ethics approval was received from the three institutes that participated in this study.

\section{Funding}

This research was funded by a Social Sciences and Humanities Research Council of Canada Insight Development Grant Number 430-2013-000556.

\section{Publisher's Note}

Springer Nature remains neutral with regard to jurisdictional claims in published maps and institutional affiliations.

Received: 8 March 2017 Accepted: 31 May 2017

Published online: 06 June 2017

\section{References}

Adams D, Gamage DT (2008) A study of leadership effectiveness in a large VET institution in Australia. Int J Educ Manag 22(3):214-228

Albashiry NM, Voogt JM, Pieters JM (2015a) Curriculum design practices of a vocational community college in a developing context: challenges and needs. Community Coll J Res Pract 39(12):1137-1152. doi:10.1080/10668926.2014.942 894

Albashiry NM, Voogt JM, Pieters JM (2015b) Improving curriculum development practices in a technical vocational community college: examining effects of a professional development arrangement for middle managers. Curr J 26(3):425-451. doi:10.1080/09585176.2015.1040041

Albashiry NM, Voogt JM, Pieters JM (2015c) Curriculum leadership in action: a tale of four community college heads of department leading a curriculum-development project. Community Coll J Res Pract 40(5):401-413. doi:10.1080/10 668926.2015 .1065775

Anderson D (2008) Productivism, vocational and professional education, and the ecological question. Vocat Learn 1:105-129. doi:10.1007/s12186-008-9007-0

Basham MJ, Campbell DF (2010) A comparative analysis between researchers, innovative practitioners, and department chairs of critical issues for turnaround leadership in community college instructional programs and services 2010 and beyond. Community Coll J Res Pract 35(1-2):50-60. doi:10.1080/10668926.2011.528708

Bound H (2011) Vocational education and training teacher professional development: tensions and context. Stud Contin Educ 33(2):107-119. doi:10.1080/0158037X.2011.554176

Bowen GA (2006) Grounded theory and sensitizing concepts. Int J Qual Methods 5(3):12-23

Briggs ARJ (2005) Middle managers in english further education colleges: understanding and modelling the role. Educ Manag Adm Leadsh 33(1):27-50

Briggs CL, Stark JS, Rowland-Poplowski J (2003) How do we know a "continuous planning" academic program when we see one? J High Educ 74(4):361-385

Brown L, Martinez M, Daniel D (2002) Community college leadership preparation: needs, perceptions, and recommendations. Community Coll Rev 30(1):45-73 
Burke KM (2014) Evidence-based instructional leadership in community colleges: a conceptual approach. Educ Act Res 22(2):221-234. doi:10.1080/09650792.2013.859091

Crossman B, Cameron R (2014) A comparative thematic review of vocational leadership literature from the USA, Great Britain and Australia. Res Post Compuls Educ 19(4):393-416

Darling-Hammond L (2006) Constructing 21st-century teacher education. J Teacher Ed 57:300-314

Darwin S (2007) The changing contexts of vocational education: implications for institutional vocational learning. J Train Res 5(1):55-71

Drodge S (2002) Managing under pressure: the management of vocational education in the British, Dutch and French systems. Res Post Compuls Educ 7(1):27-43

Ellström E, Ellström PE (2014) Learning outcomes of a work-based training programme. Euro J Train Dev 38(3):180-197. doi:10.1108/EJTD-09-2013-0103

Geijsel FP, Sleegers PJC, Stoel RD, Kruger ML (2009) The effect of teacher psychological and school organizational and leadership factors on teachers' professional learning in Dutch schools. Elem Sch J 109:406-427

Gmelch WH, Ward K, Roberts D, Hirsch S (2016) The call for leadership: why department chairs serve, what they do, how they are prepared and how long they serve. Paper presented at the annual meeting of the University Center of Educational Administration, Detroit, Ml, November 2016

Hallinger P (2011) Leadership for learning: lessons from 40 years of empirical research. J Educ Adm 49(2):125-142. doi:10.1108/09578231111116699

Harris R, Simons M, Hill D, Smith E, Pearce R, Blakeley J et al. (2001) The changing role of staff development for teachers and trainers in vocational education and training. Leabrook, Australia: The National Centre for Vocational Education Research (NCVER) Ltd. http://www.ncver.edu.au/publications/595.html. Accessed 18 May 2017

Hoekstra A, Crocker JR (2015a) Design, implementation, and evaluation of an ePortfolio approach to support faculty development in vocational education. Stud Educ Eval 46:61-73

Hoekstra A, Crocker JR (2015b) ePortfolios: enhancing professional learning of vocational educators. Vocat Learn 8(3):353-372. doi:10.1007/s12186-015-9133-4

Hoekstra A, Brekelmans M, Beijaard D, Korthagen F (2009) Experienced teachers' informal learning: learning activities and changes in behaviour and cognition. Teach Teach Educ 25(5):663-673. doi:10.2016/j.tate.2008.12.007

Hoekstra A, Kuntz J, Newton P (2017) Professional learning of instructors in vocational and professional education. Prof Dev Educ. doi:10.1080/19415257.2017.1280523

Jennings-Sweeney K (2012) The community college department chair and curriculum leadership: managing learning and learning to manage. Dissertation, University of Massachusetts

Knight PT, Trowler PR (2000) Department-level cultures and the improvement of learning and teaching. Stud High Educ 25(1):69-83

Kwakman CHE (2003) Factors affecting teachers' participation in professional learning activities. Teach Teach Educ 19:149-170. doi:10.1016/S0742-051X(02)00101-4

Kyndt E, Gijbels D, Grosemans I, Donche V (2016) Teachers' everyday professional development: mapping informal learning activities, antecedents, and learning outcomes. Rev Educ Res 86(4):1111-1150. doi:10.3102/0034654315627864

Leithwood K, Jantzi D (2006) Transformational school leadership for large scale reform: effects on students, teachers, and their classroom practices. Sch Effect Sch Improv 17:e201-e227

Martin E, Trigwell K, Prosser M, Ramsden P (2003) Variation in the experience of leadership of teaching in higher education. Stud High Educ 28(3):247-259

Miles MB, Huberman AM (1994) Qualitative data analysis: an expanded sourcebook. Sage, Thousand Oaks

Newton P, Tunison S, Viczko M (2010) The school principal's role in large-scale assessment. Can J Educ Adm Policy 105:1-24

Nicholls G (2001) Professional development in higher education: new dimensions and directions. Stylus Publishing Inc, Sterling

Oude Groote Beverborg A, Sleegers PJC, Endedijk MD, van Veen K (2015a) Towards sustaining levels of reflective learning: how do transformational leadership, task interdependence, and self-efficacy shape teacher learning in schools? Societies 5:187-219. doi:10.3390/soc5010187

Oude Groote Beverborg A, Sleegers PJC, Endedijk MD, van Veen K (2015b) Promoting VET teachers'individual and social learning activities: the empowering and purposeful role of transformational leadership, interdependence, and selfefficacy. Empir Res Vocat Educ Training 7(5):1-20

Oude Groote Beverborg A, Sleegers PJC, van Veen K (2015c) Fostering teacher learning in VET colleges: do leadership and teamwork matter? Teach Teach Educ 48:22-33. doi:10.1016/j.tate.2015.01.015

Prosser M (2013) Quality teaching quality learning. In: Salter DJ (ed) Cases on quality teaching practices in higher education. IGI Global, Vancouver

Ramsden P, Prosser M, Trigwell K, Martin E (2007) University teachers' experiences of academic leadership and their approaches to teaching. Learn Instr 17:140-155

Robinson V, Lloyd C, Rowe K (2008) The impact of leadership on student outcomes: an analysis of the differential effects of leadership types. Educ Admin Q 44(5):635-674

Roxa T, Martensson K, Alveteg M (2011) Understanding and influencing teaching and learning cultures at university: a network approach. High Educ 62:99-111

Runhaar P, Sanders K (2013) Implementing Human Resources Management (HRM) within Dutch VET institutions: examining the fostering and hindering factors. J Vocat Educ Train 65(2):236-255. doi:10.1080/13636820.2013.783612

Runhaar P, Sanders K, Yang H (2010) Stimulating teachers' reflection and feedback asking: an interplay of self-efficacy, learning goal orientation, and transformational leadership. Teach Teach Educ 26:1154-1161

Scheerens J, Bosker R (1997) The foundations of educational effectiveness. Pergamon, Oxford

Sirk M, Liivik R, Loogma K (2016) Changes in the professionality of vocational teachers as viewed through the experiences of long-serving vocational teachers in Estonia. Empir Res Vocat Educ Train 8(13):1-26 
Sleegers P, Bolhuis S, Geijsel F (2005) School improvement within a knowledge economy: fostering professional learning from a multidimensional perspective. In: Bascia N, Cumming A, Datnow A, Leithwood K, Livingstone D (eds) International handbook of educational policy. Springer, Dordrecht

Smith R (2002) The role of the university head of department: a survey of two British universities. Educ Manag Adm 30(3):293-312

Stiehl R, Lewchuk L (2008) The outcomes primer: reconstructing the college curriculum. The Learning Organization, Corvallis

The Carnegie Foundation for the Advancement of Teaching (2008) Strengthening pre-collegiate education in community colleges: project summary and recommendations. The Carnegie Foundation, Stanford

Tripney JS, Hombrados JG (2013) Technical and vocational education and training (TVET) for young people in low- and middle-income countries: a systematic review and meta-analysis. Empir Res Vocat Educ Train 5(3):1-14

Van Schalkwyk S, Leibowitz B, Herman N, Farmer J (2015) Reflections on professional learning: choices, context and culture. Stud Educ Eval 46:4-10

Yin RK (1993) Applications of case study research. Sage, London

ZakrajsekT (2014) Developing learning in faculty: seeking expert assistance from colleagues. New Dir High Educ $165: 63-73$

\section{Submit your manuscript to a SpringerOpen ${ }^{\circ}$} journal and benefit from:

Convenient online submission

Rigorous peer review

- Immediate publication on acceptance

- Open access: articles freely available online

- High visibility within the field

Retaining the copyright to your article

Submit your next manuscript at $\boldsymbol{s p r i n g e r o p e n . c o m ~}$ 